\title{
Failed treatment of long bone nonunions with low intensity pulsed ultrasound
}

\author{
Bahram Biglari $^{1} \cdot$ Timur Mert Yildirim ${ }^{2}$ - Tyler Swing ${ }^{2}$ ' Thomas Bruckner ${ }^{3}$. \\ Wolfgang Danner ${ }^{1} \cdot$ Arash Moghaddam $^{2}$
}

Received: 11 April 2016/Published online: 6 July 2016

(C) The Author(s) 2016. This article is published with open access at Springerlink.com

\begin{abstract}
Introduction The use of low intensity pulsed ultrasound (LIPUS) in the treatment of nonunions is still controversial. The present study is concerned with whether this procedure has a clinical use and which cofactors influence its therapeutic results.

Methods In this prospective, single institution, observational study, data from October 2010 to October 2013 from 61 nonunions in 60 patients treated with EXOGEN $^{\circledR}$ LIPUS therapy were analysed. The average age was $45.4 \pm 9.81$ (18-63) years. Treatment was primarily done on long bones of the lower extremity $(75.4 \%)$. All 61 nonunions were
\end{abstract}

Arash Moghaddam

arashmoghaddam@web.de

Bahram Biglari

bahram.biglari@bgu-ludwigshafen.de

Timur Mert Yildirim

timur.yildirim@hotmail.com

Tyler Swing

tws4g@virginia.edu

Thomas Bruckner

bruckner@imbi.uni-heidelberg.de

Wolfgang Danner

wolfgang.danner@bgu-ludwigshafen.de

1 Department of Paraplegiology and Technical Orthopaedics, BG Trauma Centre Ludwigshafen, Ludwig-Guttmann-Str. 13, 67071 Ludwigshafen, Germany

2 HTRG-Heidelberg Trauma Research Group, Centre for Orthopaedics, Trauma Surgery and Spinal Cord Injury, Heidelberg University Hospital, Schlierbacher Landstraße 200a, 69118 Heidelberg, Baden-Württemberg, Germany

3 Institute of Medical Biometry and Informatics, University of Heidelberg, Im Neuenheimer Feld 305, 69120 Heidelberg, Germany examined after treatment, and the rate of healing as well as functional and subjective results were evaluated. Based on clinical and radiological findings, patients were divided into two groups: G1-successful treatment; and G2-unsuccessful treatment. Groups were compared to one another to identify possible factors influencing treatment.

Results Twenty (32.8\%) patients showed bone consolidation with an average time of healing of 5.3 (2-7) months. In patients without successful treatment, who underwent revision surgery instead, full weight bearing took on average 3.7 months longer, and they were able to return to work 6.8 months later. Most of the treated patients (70.5\%) reported no improvement in pain. In G2, 12 $(29.3 \%)$ patients suffered in their previous history from osteitis; in G1 there were only two patients (10\%) $(p=0.012)$. There were further significant differences in the age of the fracture, the type of osteosynthesis, the gap size, as well as the NUSS score.

Conclusion Despite patients being chosen strictly according to EXOGEN ${ }^{\circledR}$ indications, only a small number of patients with nonunions who underwent LIPUS therapy experienced successful treatment (32.8\%). Overall, its use resulted in a clear delay in the time of treatment, so that according to our results, the use of LIPUS should be seen critically in long bone nonunions and use should be made on a case-by-case basis.

Keywords Nonunion - Delayed fracture healing - Low intensity pulsed ultrasound · LIPUS · EXOGEN ${ }^{\circledR}$

\section{Introduction}

Nonunion is often associated with pain and enormous reductions in the quality of life. Also, it is associated with longer disease duration, as well as social and economic 
consequences [1]. The point in time at which a fracture with delayed healing is considered a nonunion is controversial [2]. Increasing certainty exists over this definition of a nonunion: when bone consolidation is expected, but does not occur without intervention according to radiological and clinical results [3]. In order to treat nonunions there are invasive and non-invasive surgical therapies available. Non-invasive treatments, such as physiotherapy and mechanical weight bearing exercises $[4,5]$ are especially important in the early phase of nonunion treatment and require sufficient mechanical stability for possible osseous regeneration. If these methods fail, then surgical intervention gains importance [6-8]. In the realm of non-invasive therapy, there are further approaches with differing biophysical methods, such as high energy extracorporeal shock wave therapy [9, 10], pulsed electromagnetic field [11], or constant direct current [12], as well as therapy with low intensity pulsed ultrasound (LIPUS) [13-15]. Experimental studies showed that through the application of a stimulating effect on cells and signal ways, there is an influence on bone healing [16-19]. A few clinical studies have shown the benefit of LIPUS [15, 20, 21]. Other studies, however, have shown contrary results [22-24]. It is still unclear, whether LIPUS has a clinically relevant use in treatment of nonunions. In addition, there are no concrete conclusions concerning which patients would benefit from such a therapy. The goal of this study is to evaluate the results of LIPUS in our patient collective and in doing contribute to answering the following questions:

1. Which patients were treated with LIPUS?

2. How successful was the treatment?

3. What co-factors influenced the results?

4. Can therapy recommendations be determined?

\section{Methods}

\section{Setting}

The given study was conducted as a prospective, singe institution, observational cohort study. Between October 2010 and October 2013, 73 chronic nonunion patients who received treatment with EXOGEN $^{\circledR}>90$ days after their last surgery, at a level 1 Trauma Centre, were included. We chose an interval of $>90$ days without intervention to minimize a possible influence of the surgery. In 13 patients, the desired treatment duration could not be achieved because they were treated with surgery before the end of therapy. Further exclusion criteria were possible pregnancy and age less than 18 years. One patient received LIPUS on two different long bones. Altogether 61 nonunions in 60 patient data sets have been evaluated. An experienced orthopaedic surgeon and a rehabilitation physician gave the indication for treatment with LIPUS according to EXOGEN ${ }^{\circledR}$ guidelines: The fracture had to have sufficient clinical stability and there must not have been any signs of current infection. Patients received follow up regularly in our ambulant facility and were examined radiologically and clinically after 6 and 12 weeks, and after 4, 5, 6, and 12 months or completion of bone consolidation. The goal of treatment was to initiate healing of nonunions. Another experienced orthopaedic team finally examined the patients after 1 year and the analysis of the radiological examinations was completed.

\section{LIPUS therapy}

All LIPUS patients in our study were treated with the same device $\left(\mathrm{EXOGEN}^{\circledR}\right.$ by Bioventus ${ }^{\circledR}$, formerly Smith and Nephew ${ }^{\circledR}$ ). Before the first treatment, the correct position of the device was controlled radiologically. After receiving the standard directions from a representative of Bioventus ${ }^{\circledR}$, patients used the device for 20 min daily. In order to ensure compliance, the EXOGEN ${ }^{\circledR}$ device tracked the daily length of treatment. The frequency was $1.5 \mathrm{MHz}$ $( \pm 5 \%)$, power was $30 \mathrm{~mW} / \mathrm{cm}^{2}( \pm 30 \%)$, pulse duration was $200 \mu \mathrm{s}( \pm 10 \%)$, and signal repetition was $1 \mathrm{kHz}$ $( \pm 10 \%)$.

\section{Evaluation of therapy}

Successful therapy was defined according to the following criteria: radiologically observed consolidation and no further surgical revision for the next year. On the other hand, therapy was unsuccessful if the nonunion did not heal and a new surgical intervention was necessary (Fig. 1).

All X-ray and CT exams performed during the study were evaluated by two orthopaedists. To assess the consolidation following criteria were used:

- Ossification in at least 3 of 4 levels.

- Secondary loosening of the implant.

- Possible secondary change in axis alignment.

The individual risk for developing a nonunion was assessed according to the presurgical nonunion score (PSN Score) (Table 1) [1]. Nonunions were classified according to non-union scoring system (NUSS) [25] (Table 2). Bone quality was evaluated according to the classification from Weber and Cech. The gap size, the Paley classification [26], the bone quality, and the bone position were evaluated. 


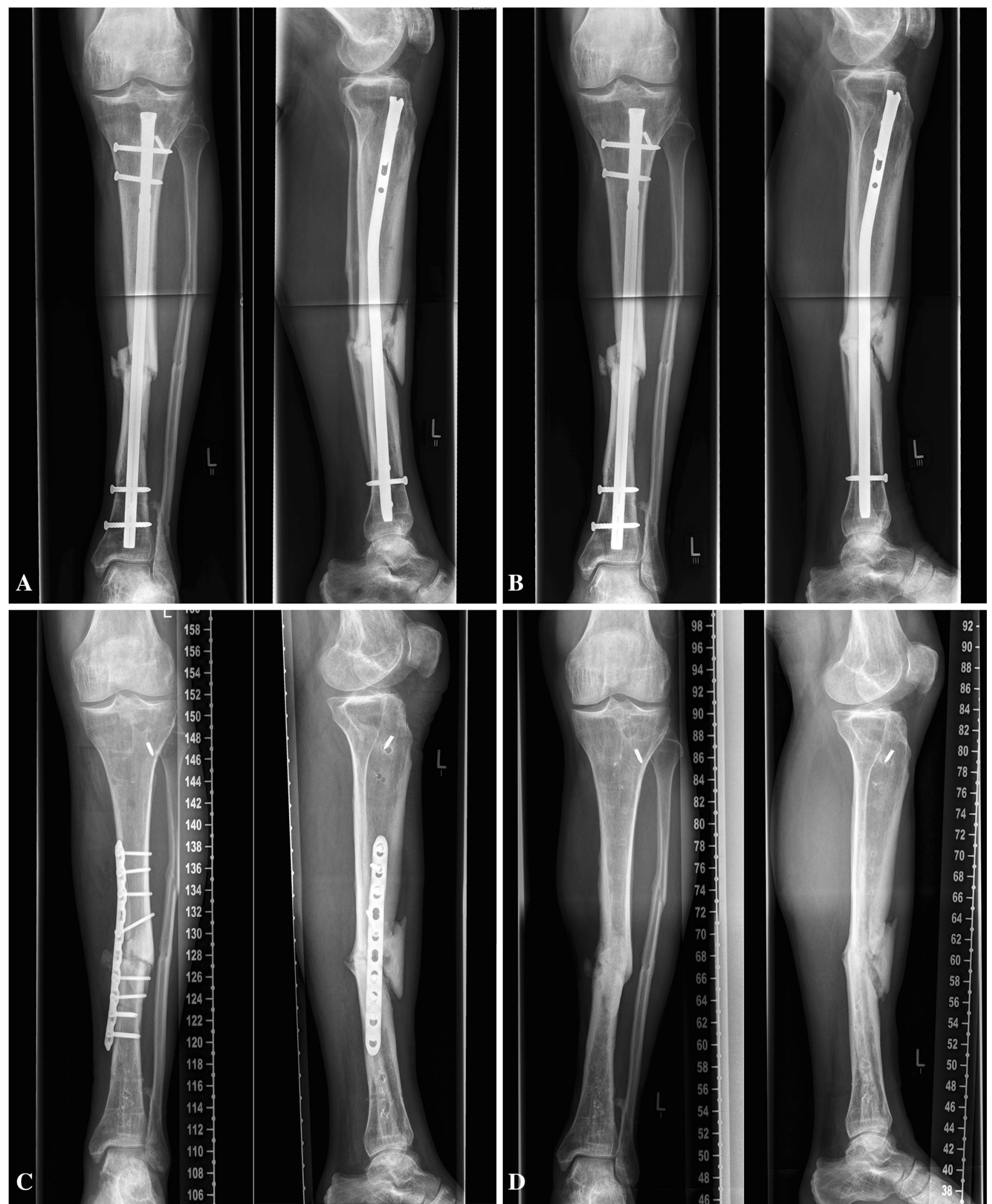

Fig. 1 Unsuccessful LIPUS treatment. A 52-year-old male patient with a tibial nonunion, a start of LIPUS 1 year after trauma, b persisting nonunion after unsuccessful LIPUS treatment, $\mathbf{c}$ revision

surgery with plate osteosynthesis including decortication, autologous spongiosa graft and BMP7 application 8 months after LIPUS, d healed nonunion, implant removal 8 months after revision surgery 
Table 1 Presurgical nonunion score (PSN Score) to estimate the individual risk of patients for delayed union of long bone fractures

\begin{tabular}{|c|c|c|c|}
\hline \multicolumn{4}{|l|}{ Localisation } \\
\hline Humerus & Prox. 4 points & Diaph. 6 points & Distal 2 points \\
\hline Forearm & Prox. 4 points & Diaph. 6 points & Distal 2 points \\
\hline Femur & Prox. 4 points & Diaph. 6 points & Distal 8 points \\
\hline Tibia & Prox. 6 points & Diaph. 8 points & Distal 4 points \\
\hline \multirow[t]{2}{*}{ Soft tissue } & $1^{\circ}$ open 4 points & $2^{\circ}$ open 6 points & $3^{\circ}$ open 10 points \\
\hline & Fasciotomy 4 points ${ }^{\mathrm{a}}$ & Previous fracture 8 points $^{\mathrm{a}}$ & Neurological disorder 6 points ${ }^{b}$ \\
\hline Smoking & Smoker 15 points & Previous smoker 5 points & Non-smoker 0 points \\
\hline Comorbidity/medication & NSAID 4 points & Bisphosphonate 6 points & Diabetes 4 points \\
\hline Type 1 & $<10$ points & Low risk & \\
\hline Type 2 & 10-20 points & Middle risk & \\
\hline Type 3 & $>20$ points & High risk & \\
\hline
\end{tabular}

See Ref. [1]

a Affected bone

b Affected limb; Prox, proximal; Diaph, diaphysal

Based on clinical and radiological evaluation as described above, patients were retrospectively divided into two groups: G1 consisted of patients with successful treatment, and G2 unsuccessful treatment (Fig. 2).

\section{Statistical analysis}

Statistical analysis was done under the guidance of an Institute for Medical Biometrics and Informatics with SPSS 21.0 (IBM $^{\circledR}$ Germany GmbH) and Excel ${ }^{\circledR} 2011$ (Microsoft ${ }^{\circledR}$ ). Depending on the scale of graphs, data were portrayed in terms of mean \pm standard deviation (minimum-maximum), percentage frequency, or median with first and third quartiles. Categorical data were evaluated with the $\chi^{2}$ test, continuous variables with the student's $t$ test. We conducted binary logistic regression analyses. The level of significance $\alpha$ was set to $5 \%$.

\section{Ethics and source of funding}

Written informed consent for participation in the study was obtained from all participants. None of the participants was underage. The study was conducted in accordance with the World Medical Association Declaration of Helsinki. The study was approved by the ethics committee of the Chamber of Medicine in Rheinland-Pfalz (837.141.08-2008 and 837.422.122012). There was no external funding source for this investigation.

\section{Results}

Sixty-one nonunions in sixty patients were included in this study. All patients were available for all follow-up dates.

\section{Patient collective}

\section{Tables 3, 4, 5}

The collective was mostly comprised of men $(91.8 \%)$. Patients were on average $45 \pm 9.81$ (18-63) years of age and had a BMI of $28.9 \pm 5.4$ (21.1-44.2). Twenty-six patients $(42.6 \%)$ were smokers (Table 3 ).

Overall, the patient collective had middle to high-risk profile. The average risk score according to the NUSS was $38.9 \pm 10.8$ (20-66) (Table 5).

Most patients received treatment of the lower extremity (Table 4). The tibia was affected in 35 patients $(57.4 \%)$, and femur in $11(18.0 \%)$ cases. There were 14 patients $(23.0 \%)$ with an osteitis in patients' history before therapy. The majority of patients acquired the fracture from a fall from great heights $(32.8 \%)$, or an injury with a motorized two-wheeled vehicle $(26.2 \%)$ (Table 4). The age of the fracture from the beginning of therapy was on average $10.4 \pm 8.9$ (3-58) months. Patients had received an average of $3.02 \pm 2.26(1-13)$ operations. At the time of therapy, 37 patients $(60.7 \%)$ had osteosynthesis with a plate, $13(21.3 \%)$ with intramedullary nailing, and 11 $(18.0 \%)$ with an external fixateur (Table 4). 
Table 2 Non-union scoring system

Score $^{\mathrm{a}}$ Max. score

The bone

Quality of the bone

Good

0

Moderate (e.g., mildly osteoporotic)

1

Poor (e.g., severe porosis or bone loss)

3

Primary injury—open or closed

Very poor (Necrotic, appears avascular or septic)

2 fracture

Closed

Open $1^{\circ}$ grade

Open $2^{\circ}-3^{\circ}$ A grade

Open $2^{\circ}-3^{\circ}$ A grade 3

Number of previous interventions on

Open $3^{\circ} \mathrm{B}-\mathrm{C}$ grade

this bone to procure healing

None

$<2$

$<4$

$>4$

Invasiveness of previous interventions

Minimally-invasive: Closed surgery (screws, k wires,...)

Internal intra-medullary (nailing)

Internal extra-medullary

Any osteosynthesis which includes bone grafting

Adequacy of primary surgery

Adequate stability

Inadequate stability

Hypertrophic

Oligotrophic

Atrophic

Anatomic alignment

Non-anatomic alignment

$0.5-1 \mathrm{~cm}$

$1-3 \mathrm{~cm}$

$>3 \mathrm{~cm}$

Soft tissues

Status

Intact

0

Previous uneventful surgery, minor scarring

Previous treatment of soft tissue defect (e.g., skin loss, local flap cover, $\quad 3$ multiple incisions, compartment syndrome, old sinuses)

Previous complex treatment of soft tissue defect (e.g., free flap) 4

Poor vascularity: absence of distal pulses, poor capillary refill, venous 5 insufficiency

Presence of actual skin lesion/defect (e.g., ulcer, sinus, exposed bone or plate) $6 \quad 6 \quad 6$

The patient

\begin{tabular}{|c|c|c|c|}
\hline ASA Grade & 1 or 2 & 0 & \\
\hline & 3 or 4 & 1 & 1 \\
\hline Diabetes & No & 0 & \\
\hline & Yes-well controlled $(\mathrm{HbA1c}<10)$ & 1 & \\
\hline & Yes-poorly controlled $(\mathrm{HbA} 1 \mathrm{c}>10)$ & 2 & 2 \\
\hline Blood tests: FBC, ESR, CRP & FBC: $\mathrm{WCC}>12$ & 1 & \\
\hline & ESR $>20$ & 1 & \\
\hline & $\mathrm{CRP}>20$ & 1 & 3 \\
\hline Clinical infection status & Clean & 0 & \\
\hline & Previously infected or suspicion of infection & 1 & \\
\hline & Septic & 4 & 4 \\
\hline
\end{tabular}


Table 2 continued

\begin{tabular}{llll}
\hline & & Score $^{\mathrm{a}}$ & Max. score \\
\hline Drugs & Steroids & 1 & 2 \\
\multirow{2}{*}{ Smoking status } & NSAIDs & 1 & 0 \\
& No & 5 & 5 \\
\hline
\end{tabular}

See Ref. [25]

${ }^{\text {a }}$ Higher score implies more difficult to procure union

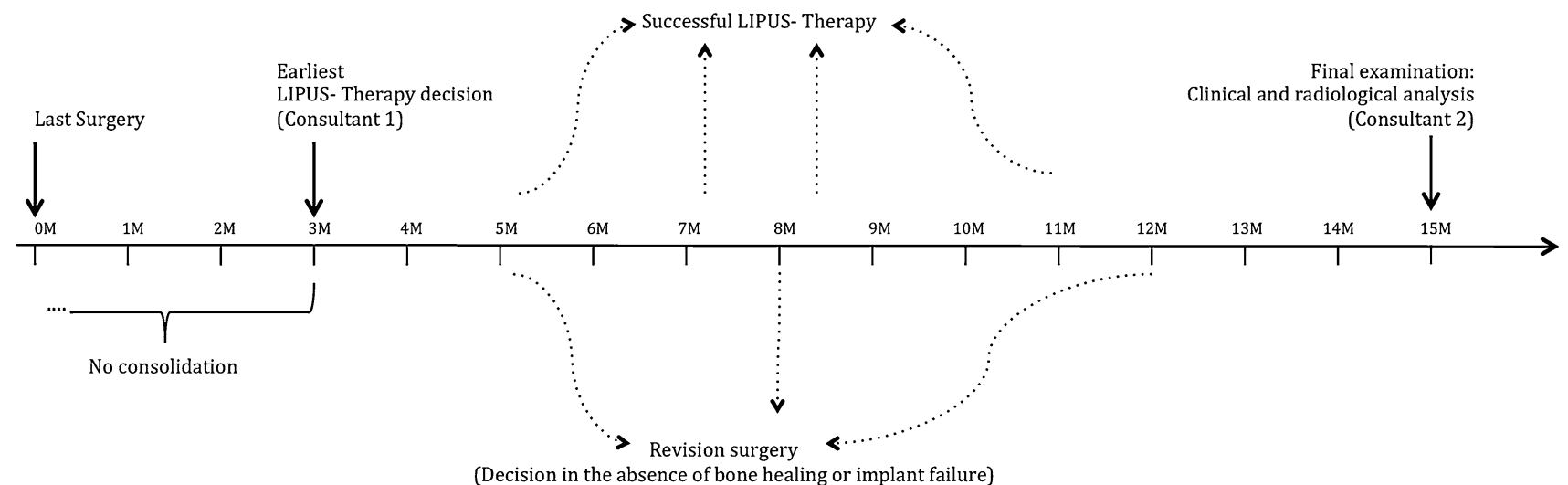

Fig. 2 Timeline of the study protocol. Patients were treated at the earliest 3 months after surgery with LIPUS. Over the course of therapy, patients healed or needed revision surgery. Final examinations occurred 1 year after LIPUS. Final examinations followed

\section{Radiological characteristics}

The average gap size was $0.67 \pm 0.55(0-3) \mathrm{cm}$. The bone quality was mostly moderate $(34.4 \%)$ to bad $(31.1 \%)$. Patients had hyper $(39.3 \%)$ und normo-trophic $(49.2 \%)$ nonunions. The average NUSS score for the entire collective was $38.9 \pm 10.8$ (20-66) (Table 5).

\section{Results of LIPUS}

Twenty cases (32.8\%) had a successful LIPUS therapy (G1), and 41 cases $(67.2 \%)$ had to receive further surgery (G2). In patients with healed nonunions there was an average time of consolidation of $5.3 \pm 1.9$ months. The average duration of therapy was $5.5 \pm 1.8$ (2-9) months.

The time from beginning LIPUS therapy to achievement of full weight bearing was on average $7.5 \pm 5.6$ (1-23) months. In 15 cases $(24.6 \%)$, full weight bearing was not reached at the end of the study (Table 6).

All patients were disabled after accident. On average, the duration of disability was $16.2 \pm 8.3$ (1.3-36) months. Twenty-four cases $(39.3 \%)$ were disabled at the end of the study.
1 year after LIPUS. In any case, the decision for LIPUS was made by a different physician (consultant 1) than the data analysis (consultant 2)

Upon completion of LIPUS, five patients (8.2\%) reported an improvement in pain, $13(21.3 \%)$ minimal improvement, 37 (60.7\%) no improvement, and one patient $(1.6 \%)$ said that pain had become more severe (Table 6).

\section{Complication}

One patient with a history of osteitis developed an abscess in the fourth week of LIPUS therapy that needed to be treated surgically.

\section{Comparison of groups}

Tables 3, 4, 5, 6

The duration until full weight bearing was achieved was significantly different between the groups. It was $5.4 \pm 3.9$ (1-14) months in the successful group and $9.1 \pm 6.1$ (1-23) months in the unsuccessful group ( $p=0.037)$. In G1, two patients (10\%) did not reach full weight bearing; in $\mathrm{G} 2$ it was $13(31.7 \%)(p=0.065)$ (Table 6). On average, patients in group 2 reached full weight bearing 3.7 months later than group 1 (Fig. 3). 
Table 3 Patient characteristics

\begin{tabular}{|c|c|c|c|c|c|c|c|}
\hline \multirow[t]{2}{*}{ Characteristic } & \multicolumn{2}{|l|}{ Total } & \multicolumn{2}{|c|}{ Successful treatment (G1) } & \multicolumn{2}{|c|}{ Unsuccessful treatment (G2) } & \multirow[t]{2}{*}{$p$ value } \\
\hline & $N=6$ & & $N=20$ & $(32.8 \%)$ & $N=41$ & $(67.2 \%)$ & \\
\hline Gender & & & & & & & 0.525 \\
\hline Male & 56 & $(91.8 \%)$ & 19 & $(33.9 \%)$ & 37 & $(66.1 \%)$ & \\
\hline Female & 5 & $(8.2 \%)$ & 1 & $(20.0 \%)$ & 4 & $(80.0 \%)$ & \\
\hline Age (years) & 45.4 & $\pm 9.81(18-63)^{\mathrm{a}}$ & 44.6 & $\pm 11.1(18-63)^{\mathrm{a}}$ & 45.9 & $\pm 9.1(18-60)^{\mathrm{a}}$ & 0.633 \\
\hline BMI & 28.9 & $\pm 5.44(21.1-40.5)^{\mathrm{a}}$ & 29.1 & $\pm 5.5(21.6-40.5)^{\mathrm{a}}$ & 28.8 & $\pm 5.4(21.1-44.2)^{\mathrm{a}}$ & 0.867 \\
\hline $\mathrm{BMI}>40$ & 5 & $(8.2 \%)$ & 1 & $(5.0 \%)$ & 4 & $(6.6 \%)$ & 0.714 \\
\hline Smoking & & & & & & & 0.485 \\
\hline Smoker & 26 & $(42.6 \%)$ & 10 & $(50.0 \%)$ & 16 & $(39.0 \%)$ & \\
\hline Previous smoker & 11 & $(18.0 \%)$ & 2 & $(10.0 \%)$ & 9 & $(22.0 \%)$ & \\
\hline Non-smoker & 24 & $(39.3 \%)$ & 8 & $(40.0 \%)$ & 16 & $(39.0 \%)$ & \\
\hline Diabetes Mellitus & & & & & & & 0.115 \\
\hline Yes & 9 & $(14.8 \%)$ & 5 & $(25.0 \%)$ & 4 & $(9.8 \%)$ & \\
\hline No & 52 & $(85.2 \%)$ & 15 & $(75.0 \%)$ & 37 & $(90.2 \%)$ & \\
\hline Combined vascular risk* & 3 & $(4.9 \%)$ & 3 & $(15.0 \%)$ & 0 & $(0.0 \%)$ & $0.011^{*}$ \\
\hline Smoking & & & & & & & 0.555 \\
\hline Diabetes Mellitus & & & & & & & 0.108 \\
\hline Arterial hypertension & 12 & $(19.7 \%)$ & 4 & $(20.0 \%)$ & 8 & $(19.5 \%)$ & \\
\hline Hypercholesterolemia & 3 & $(4.9 \%)$ & 1 & $(5.0 \%)$ & 2 & $(4.9 \%)$ & \\
\hline Hypothyroidism & 4 & $(6.6 \%)$ & 1 & $(5.0 \%)$ & 3 & $(7.3 \%)$ & \\
\hline Asthma & 2 & $(3.3 \%)$ & 1 & $(5.0 \%)$ & 1 & $(2.4 \%)$ & \\
\hline Degree of physical activity during work & & & & & & & 0.423 \\
\hline Low & 14 & $(23.0 \%)$ & 4 & $(20.0 \%)$ & 10 & $(24.4 \%)$ & \\
\hline Medium & 17 & $(27.9 \%)$ & 4 & $(20.0 \%)$ & 13 & $(31.7 \%)$ & \\
\hline High & 29 & $(47.5 \%)$ & 12 & $(60.0 \%)$ & 17 & $(41.5 \%)$ & \\
\hline PSN Score [1] & 18.6 & $\pm 9(4-43)^{\mathrm{a}}$ & 17.3 & $\pm 8.3(6-31)^{\mathrm{a}}$ & 19.2 & $\pm 9.2(6-43)^{\mathrm{a}}$ & 0.455 \\
\hline
\end{tabular}

* Significant differences between the groups; level of significance $\alpha$ was set to $5 \%$

a Average \pm standard deviation (minimum-maximum)

Also the length of disability was significantly different between groups. In the consolidated group it was $12.2 \pm 8.1(1.3-36)$ months, in the non-consolidated group $19 \pm 7.3(5-36)(p=0.017)$.

In $\mathrm{G} 1,5$ patients $(25 \%)$ stayed disabled after therapy, in G2 $19(46.3 \%)(p=0.122)$ (Table 6). Patients in G2 returned to work 6.8 months later than G1 (Fig. 3).

There was a difference in the standardized subjective evaluation of therapy between G1 and G2. Patients in G1 reported significantly more lessening of pain $(p=0.004)$. The length of treatment did not significantly differ between groups (G1: $5.3 \pm 1.9$ months; G2: $5.6 \pm 1.8$ months). There were no significant differences amongst groups regarding patient characteristics (Table 3). In G1, there were only 2 cases of previous infection; G2 had 12 $(p=0.012) \quad$ (Table 4$)$. The binary logistic regression model had the following results: Patients with past osteitis had a 4.6- (95\% CI 1.5-14.7) fold higher relative risk of treatment failure compared to patients without infection in prehistory. The age of the fracture at the beginning of treatment differed between G1 and G2 significantly [G1: $7.2 \pm 3.8$ (3-17) months; G2: $11.9 \pm 10.2$ (3-58) months] $(p=0.011)$. Furthermore we detected a significant difference between $\mathrm{G} 1$ and $\mathrm{G} 2$ in the type of osteosynthesis used at the time of the therapy ( $p=0.012)$ (Fig. 4). Consolidated patients were more frequently treated with plate osteosynthesis ( $p=0.007)$, non-consolidated with external fixation $(p=0.011)$. The binary logistic regression model had the following results: Nonunions treated with plate osteosynthesis had a 6.0- (95\% CI 1.5-23.5) fold higher relative chance of success of LIPUS therapy compared to treatment with other surgical procedures.

The average gap size before therapy in the successful group was $0.46 \pm 0.29(0-1) \mathrm{cm}$, in the unsuccessful group, $0.77 \pm 0.62 \quad(0.2-3) \quad \mathrm{cm} \quad(p=0.01) \quad$ (Table 5; Fig. 5a). 
Table 4 Nonunion characteristics before LIPUS

\begin{tabular}{|c|c|c|c|c|c|c|c|}
\hline \multirow[t]{2}{*}{ Characteristic } & \multicolumn{2}{|l|}{ Total } & \multicolumn{2}{|c|}{ Successful treatment (G1) } & \multicolumn{2}{|c|}{ Unsuccessful treatment (G2) } & \multirow[t]{2}{*}{$p$ value } \\
\hline & $N=61$ & & $N=20$ & $(32.8 \%)$ & $N=41$ & $(67.2 \%)$ & \\
\hline Treated bone & & & & & & & 0.656 \\
\hline Humerus & 7 & $(11.5 \%)$ & 3 & $(15.0 \%)$ & 4 & $(9.8 \%)$ & \\
\hline Radius & 3 & $(4.9 \%)$ & 2 & $(10.0 \%)$ & 1 & $(2.4 \%)$ & \\
\hline Femur & 11 & $(18.0 \%)$ & 3 & $(15.0 \%)$ & 8 & $(19.5 \%)$ & \\
\hline Tibia & 35 & $(57.4 \%)$ & 11 & $(55.0 \%)$ & 24 & $(58.5 \%)$ & \\
\hline Others & 5 & $(8.2 \%)$ & 1 & $(5.0 \%)$ & 4 & $(9.8 \%)$ & \\
\hline Type of fracture & & & & & & & 0.245 \\
\hline Closed & 44 & $(72.1 \%)$ & 17 & $(85.0 \%)$ & 27 & $(65.9 \%)$ & \\
\hline Open $1^{\circ}$ & 3 & $(4.9 \%)$ & 1 & $(5.0 \%)$ & 2 & $(4.9 \%)$ & \\
\hline Open $2^{\circ}$ & 7 & $(11.5 \%)$ & 2 & $(10.0 \%)$ & 5 & $(12.2 \%)$ & \\
\hline Open $3^{\circ}$ & 7 & $(11.5 \%)$ & 0 & $(0.0 \%)$ & 7 & $(17.1 \%)$ & \\
\hline Osteitis in patients history* & 14 & $(23.0 \%)$ & 2 & $(10.0 \%)$ & 12 & $(29.3 \%)$ & $0.012 *$ \\
\hline Mechanism of injury & & & & & & & 0.810 \\
\hline Fall from $>1 \mathrm{~m}$ & 20 & $(32.8 \%)$ & 8 & $(40.0 \%)$ & 12 & $(29.3 \%)$ & \\
\hline Motorcycle accident & 16 & $(26.2 \%)$ & 5 & $(25.0 \%)$ & 11 & $(26.8 \%)$ & \\
\hline Car accident & 9 & $(14.8 \%)$ & 2 & $(10.0 \%)$ & 7 & $(17.1 \%)$ & \\
\hline Crushing trauma & 16 & $(26.2 \%)$ & 5 & $(25.0 \%)$ & 11 & $(26.8 \%)$ & \\
\hline Circumstances of injury & & & & & & & 0.615 \\
\hline Work accident & 53 & $(86.9 \%)$ & 18 & $(90.0 \%)$ & 35 & $(85.4 \%)$ & \\
\hline Leisure related & 8 & $(13.1 \%)$ & 2 & $(10.0 \%)$ & 6 & $(14.6 \%)$ & \\
\hline Fracture age (months)* & 10.36 & $\pm 8.89(3-58)^{\mathrm{a}}$ & 7.2 & $\pm 3.8(3-17)^{\mathrm{a}}$ & 11.9 & $\pm 10.3(3-58)^{\mathrm{a}}$ & $0.011 *$ \\
\hline Number of previous surgeries & 3.02 & $\pm 2.26(1-13)^{\mathrm{a}}$ & 2.7 & $\pm 2.2(1-9)^{\mathrm{a}}$ & 3.2 & $\pm 2.3(1-13)^{\mathrm{a}}$ & 0.349 \\
\hline$\geq 4$ Surgeries & 18 & $(29.5 \%)$ & 4 & $(20.0 \%)$ & 14 & $(34.1 \%)$ & \\
\hline Surgical treatment* & & & & & & & $0.012 *$ \\
\hline Osteosynthesis plate* & 37 & $(60.7 \%)$ & 17 & $(85.0 \%)$ & 20 & $(48.8 \%)$ & $0.007 *$ \\
\hline Intramedullary nailing & 13 & $(21.3 \%)$ & 3 & $(15.0 \%)$ & 10 & $(24.4 \%)$ & \\
\hline External fixation* & 11 & $(18.0 \%)$ & 0 & $(0.0 \%)$ & 11 & $(26.8 \%)$ & $0.011^{*}$ \\
\hline
\end{tabular}

* Significant differences between the groups; level of significance $\alpha$ was set to $5 \%$

a Average \pm standard deviation (minimum-maximum)

Overall, G1 and G2 differed in the NUSS Score of nonunion $(p=0.034)$. The NUSS Score in the successful group was $34.7 \pm 8.9$ (24-54) points; in the unsuccessful group it was $41 \pm 11$ (24-66) (Table 5; Fig. 5b).

\section{Discussion}

In this observational study, 61 nonunions were treated with LIPUS. All patients took part in follow-up. The LIPUS treatment was only successful in 20 nonunions $(32.8 \%)$ of the observed patients. The strength of this study is the low dropout rate and the regular follow-up scheme. This allowed one to observe the course of the healing process in all patients over an entire year. Two Different physician teams did the indication and analysis of LIPUS to avoid observer bias. No author had any potential financial or personal competing interests that might have influenced the results. The weakness of the study was the lack of a prospective comparison group.

\section{Success rate of LIPUS}

The primary therapy goal was to heal nonunions through LIPUS therapy. This was observed in only $32.8 \%$ of the cases. The average time to healing was $5.3 \pm 1.9$ (2-7) months, which is comparable to results from former studies [27].

In the literature, various rates of healing for LIPUS that range between 55 and $88 \%$ have been reported $[14,15,20,21,27-29]$. Because of the high healing rates some authors see LIPUS as an effective alternative to surgery 
Table 5 Blinded evaluation of pre-therapeutic images

\begin{tabular}{|c|c|c|c|c|c|c|c|}
\hline \multirow[t]{2}{*}{ Characteristic } & \multicolumn{2}{|l|}{ Total } & \multicolumn{2}{|c|}{ Successful treatment $(\mathrm{G} 1)$} & \multicolumn{2}{|c|}{ Unsuccessful treatment (G2) } & \multirow[t]{2}{*}{$p$ value } \\
\hline & $N=61$ & & $N=20$ & $(32.8 \%)$ & $N=41$ & $(67.2 \%)$ & \\
\hline Defect gap $(\mathrm{cm}) *$ & 0.67 & $\pm 0.55(0-3)^{\mathrm{a}}$ & 0.46 & $\pm 0.29(0-1)^{\mathrm{a}}$ & 0.77 & $\pm 0.62(0.2-3)^{\mathrm{a}}$ & $0.01 *$ \\
\hline Paley Classification* & & & & & & & $0.034 *$ \\
\hline Type A & 53 & $(86.9 \%)$ & 20 & $(100.0 \%)$ & 33 & $(80.5 \%)$ & \\
\hline Type B & 8 & $(13.1 \%)$ & 0 & $(0.0 \%)$ & 8 & $(19.5 \%)$ & \\
\hline Quality of the bone & & & & & & & 0.639 \\
\hline Good & 15 & $(24.6 \%)$ & 6 & $(30.0 \%)$ & 9 & $(22.0 \%)$ & \\
\hline Moderate & 21 & $(34.4 \%)$ & 6 & $(30.0 \%)$ & 15 & $(36.6 \%)$ & \\
\hline Poor & 19 & $(31.1 \%)$ & 5 & $(25.0 \%)$ & 14 & $(34.1 \%)$ & \\
\hline Very poor & 6 & $(9.8 \%)$ & 3 & $(15.0 \%)$ & 3 & $(7.3 \%)$ & \\
\hline Weber and Cech group & & & & & & & 0.167 \\
\hline Hypterophic & 24 & $(39.3 \%)$ & 5 & $(25.0 \%)$ & 19 & $(46.3 \%)$ & \\
\hline Normotrophic & 30 & $(49.2 \%)$ & 13 & $(65.0 \%)$ & 17 & $(41.5 \%)$ & \\
\hline Oligotrophic & 4 & $(6.6 \%)$ & 2 & $(10.0 \%)$ & 2 & $(4.9 \%)$ & \\
\hline Atrophic & 3 & $(4.9 \%)$ & 0 & $(0.0 \%)$ & 3 & $(7.3 \%)$ & \\
\hline Bone alignment & & & & & & & 0.366 \\
\hline Bone alignment & 41 & $(67.2 \%)$ & 15 & $(75.0 \%)$ & 26 & $(63.4 \%)$ & \\
\hline Non-anatomic alignment & 20 & $(32.8 \%)$ & 5 & $(25.0 \%)$ & 15 & $(36.6 \%)$ & \\
\hline NUSS* & 38.9 & $\pm 10.8(20-66)^{\mathrm{a}}$ & 34.7 & $\pm 8.9(24-54)^{\mathrm{a}}$ & 41.0 & $\pm 11.1(24-66)^{\mathrm{a}}$ & $0.034 *$ \\
\hline
\end{tabular}

* Significant differences between the groups; level of significance $\alpha$ was set to $5 \%$

a Average \pm standard deviation (minimum-maximum)

Table 6 Outcome of LIPUS-therapy

\begin{tabular}{|c|c|c|c|c|c|c|c|}
\hline \multirow{3}{*}{$\begin{array}{l}\text { Characteristic } \\
\text { Full weight-bearing (months) }{ }^{\mathrm{b}, *}\end{array}$} & \multirow{2}{*}{\multicolumn{2}{|c|}{$\begin{array}{l}\text { Total } \\
N=61\end{array}$}} & \multicolumn{2}{|c|}{$\begin{array}{l}\text { Successful treatment } \\
\text { (G1) }\end{array}$} & \multicolumn{2}{|c|}{$\begin{array}{l}\text { Unsuccessful treatment } \\
\text { (G2) }\end{array}$} & \multirow{3}{*}{$\begin{array}{c}p \text { value } \\
0.037^{*}\end{array}$} \\
\hline & & & \multirow{2}{*}{$\begin{array}{l}N=20 \\
5.4\end{array}$} & \multirow{2}{*}{$\frac{(32.8 \%)}{ \pm 3.9(1-14)^{\mathrm{a}}}$} & \multirow{2}{*}{$\frac{N=41}{9.1}$} & \multirow{2}{*}{$\frac{(67.2 \%)}{ \pm 6.1(1-23)^{\mathrm{a}}}$} & \\
\hline & 7.5 & $\pm 5.6(1-23)^{\mathrm{a}}$ & & & & & \\
\hline Full weight-bearing not achieved & 15 & $(24.6 \%)$ & 2 & $(10.0 \%)$ & 13 & $(31.7 \%)$ & 0.065 \\
\hline Full weight-bearing possible before LIPUS- therapy & 7 & $(11.5 \%)$ & 1 & $(5.0 \%)$ & 6 & $(15.0 \%)$ & 0.144 \\
\hline Time out of work (months)* & 16.2 & $\pm 8.3(1.3-36)^{\mathrm{a}}$ & 12.2 & $\pm 8.1(1.3-36)^{\mathrm{a}}$ & 19.0 & $\pm 7.3(5-36)^{\mathrm{a}}$ & $0.017^{*}$ \\
\hline Disability after therapy & 24 & $(39.3 \%)$ & 5 & $(25.0 \%)$ & 19 & $(46.3 \%)$ & 0.122 \\
\hline Subjective evaluation of pain* & & & & & & & $0.004 *$ \\
\hline Improvement & 5 & $(8.2 \%)$ & 5 & $(25.0 \%)$ & 0 & $(0.0 \%)$ & \\
\hline Minimal improvement & 13 & $(21.3 \%)$ & 5 & $(25.0 \%)$ & 8 & $(19.5 \%)$ & \\
\hline No change & 37 & $(60.7 \%)$ & 8 & $(40.0 \%)$ & 29 & $(70.7 \%)$ & \\
\hline Worsening & 1 & $(1.6 \%)$ & 0 & $(0.0 \%)$ & 1 & $(2.4 \%)$ & \\
\hline No pain & 5 & $(8.2 \%)$ & 2 & $(10.0 \%)$ & 3 & $(7.3 \%)$ & \\
\hline
\end{tabular}

* Significant differences between the groups; level of significance $\alpha$ was set to $5 \%$

a Average \pm standard deviation (minimum-maximum)

b Surgical intervention in unsuccessful LIPUS-therapy

$[27,29]$. The most recent study with a total number of 767 analysed chronic nonunions from Zura et al. showed a healing rate of $86.2 \%$. The authors concluded that LIPUS could be an effective alternative to surgical revision in the treatment of nonunions [27]. However, this conclusion shows some weaknesses that should be taken into consideration. 
Fig. 3 Delay in time of treatment in G2. Patients from the unsuccessful group had an average additional time to full weight-bearing of 3.7 months and an average additional time out of work of 6.8 months; mean \pm standard deviation (minimum-maximum)

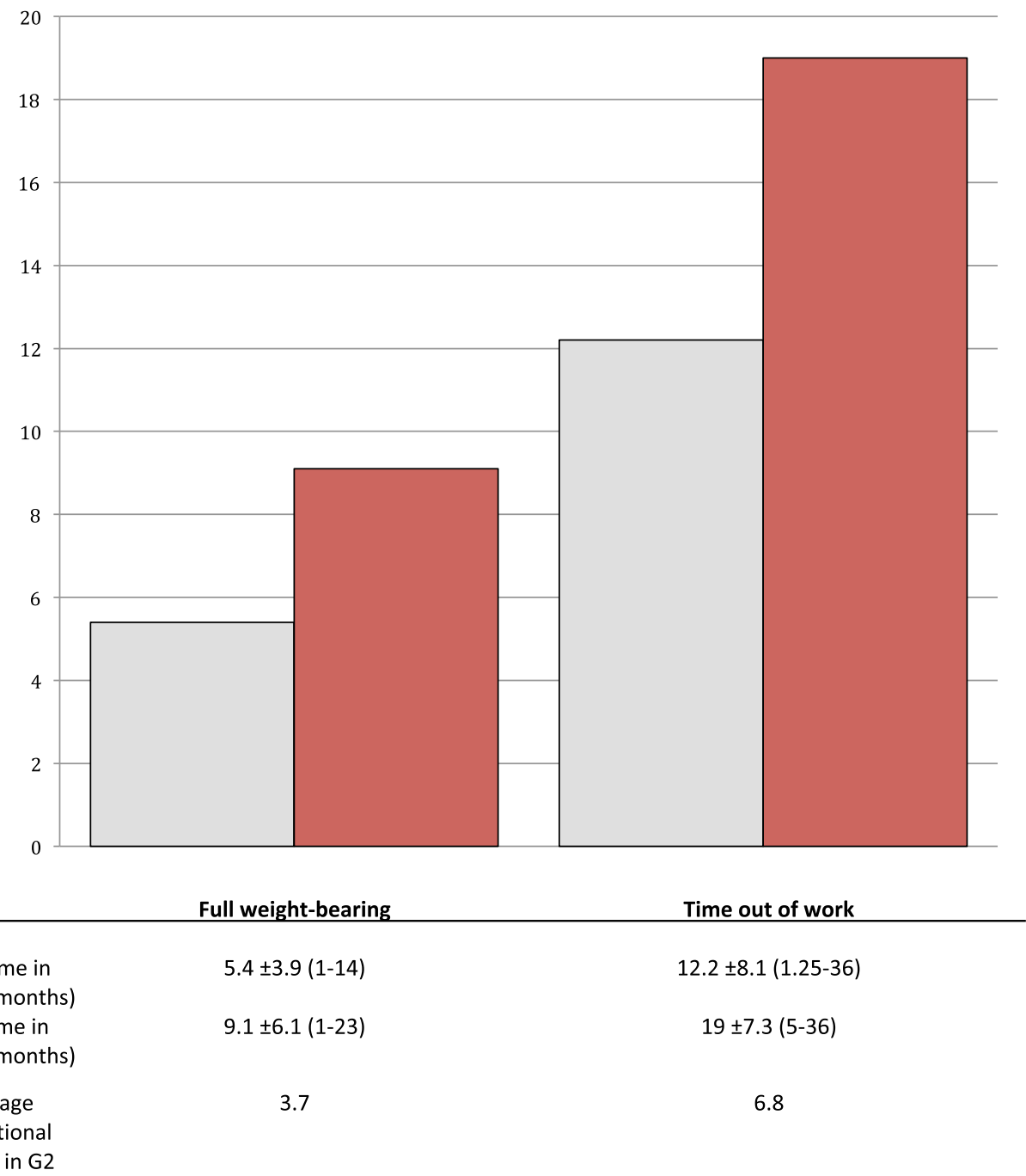

The indication criteria for surgical treatment of nonunions differ greatly from those for LIPUS. For example, LIPUS treatment needs compulsively mechanical stability of the nonunion site [15]. In addition, a small gap size is important for LIPUS treatment success [15]. In the presented study we found different other factors, which may affect the outcome, like a previous infection of the bone or an overall challenging nonunion (high NUSS Score). Because nonunions that did not meet the LIPUS treatment criteria have been treated surgically, a positive selection of the patient collective, which might have biased the results, can be assumed. To make a better statement on a possible alternative to surgery, studies should classify nonunions more differentiated and stratify the risk by supplying more detailed information on the nonunions characteristics or using scoring systems, like the NUSS. Furthermore, in this study only 91 cases have been chronic nonunion patients who received LIPUS $>90$ days after their last surgery [27]. Therefore, a possible influence of the last surgery cannot be excluded. In the presented study we only included patients who did not receive any intervention for 90 days to minimize a possible bias. Another problem might arise from the fact that there has not been a standardized follow-up scheme in this study. This makes it difficult to assess the healing process in a standardized way. All together the recent study from Zura et al. presents a highly selected patient collective and might result in misleading conclusions [27].

In the only randomized controlled study on LIPUS treatment including 101 chronic nonunion patients, 51 patients were treated with an EXOGEN ${ }^{\circledR}$ device, and 50 patients with a sham device. There was no significant difference in the rate of healing between intervention and placebo groups: the rate of healing for the EXOGEN ${ }^{\circledR}$ group was $65 \%$ (33/51), and placebo $46 \%$ (23/50) [20].

The rate of healing in our collective was $32.8 \%$, below that of 55-88 \% given in the literature [14, 15, 20, 21, 27, 28]. One possible reason for the low healing rate is the high 
Fig. 4 Surgical treatment before LIPUS Therapy. Asterisk indicates a significant difference in operative treatment between the successful and unsuccessful group
Fig. 5 Distribution of gap size and NUSS Score. a Distribution of gap size in cm: Patients with unsuccessful treatment showed a significantly larger bone gap $(p=0.01)$. b Distribution of NUSS Scores: Patients with unsuccessful treatment showed a significantly higher NUSS Score $(p=0.034)$

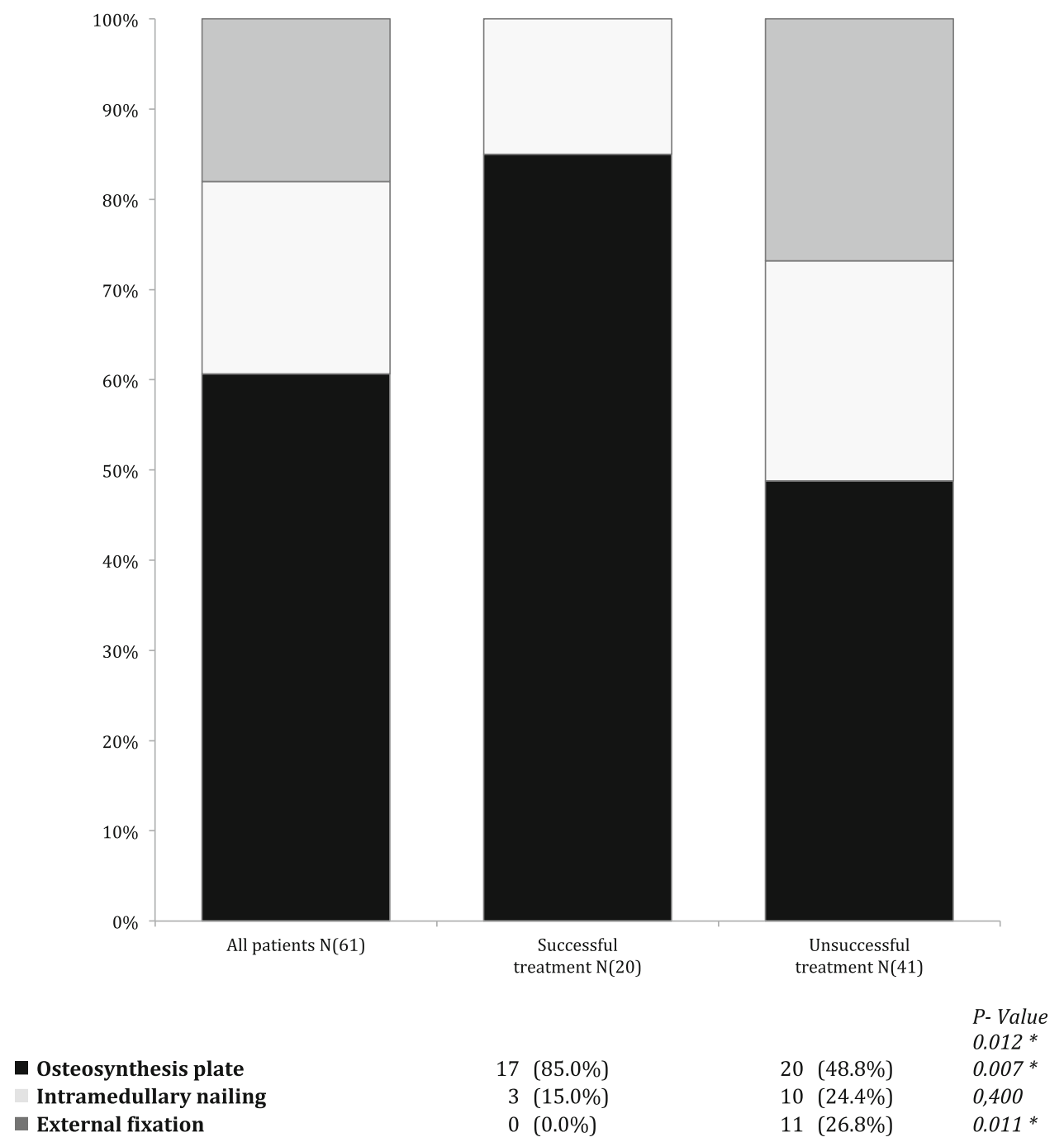

$\begin{array}{ll}3 & (15.0 \%) \\ 0 & (0.0 \%)\end{array}$
$0.012 *$

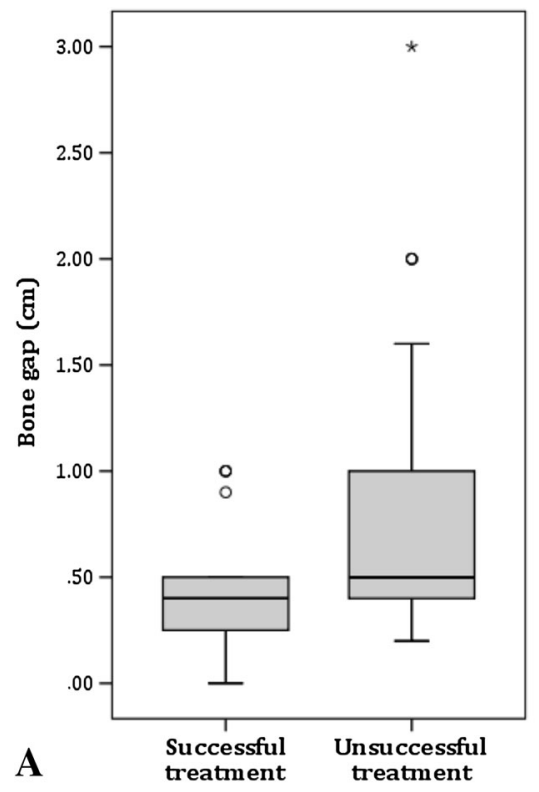

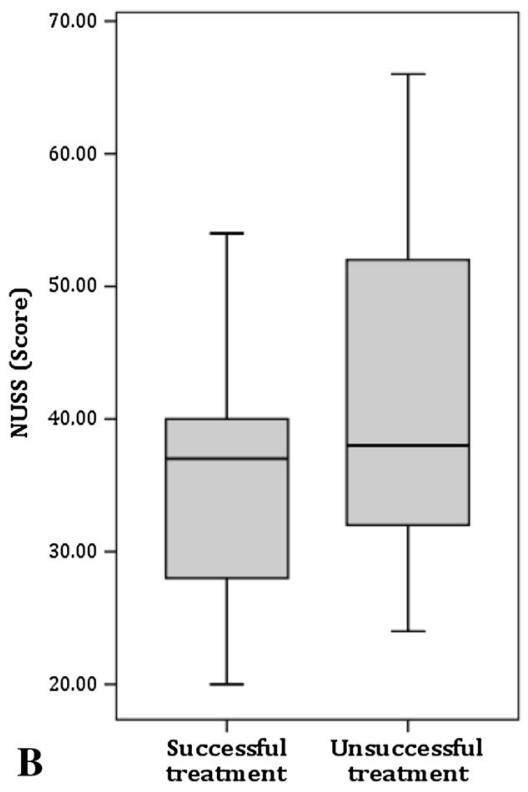


number of difficult nonunions in our patient collective. The patients had an elevated average NUSS Score of $38.9 \pm 10.8$ (20-66). Another possible explanation for the poor results in our collective is that LIPUS was presented as an alternative for many patients after a string of unsuccessful operative interventions. On average, our collective had had three surgeries, and almost one-third of the collective $(29.5 \%)$ over four times. In a study from 2001 with a rate of healing of $86 \%$ patients had only received an average of 1.4 previous operations [29]. Through the high number of failed previous operations in our collective, it can be assumed that a negative selection took place.

\section{Treatment Indication}

In our study, patients with small gap sizes and a low NUSS score benefited most from LIPUS treatment (Table 5). Patients with general risk factors such as advanced age or high BMI, as well as diabetes mellitus have shown no significant difference in treatment outcome (Table 3). Patients had a high risk of developing nonunions apparent by looking at the PSN Score showing that $75.4 \%$ had a middle or high risk of developing a nonunion. Therefor we assume that LIPUS treatment should only be considered as a treatment option for a highly selected patient collective with low risk factors.

\section{Complications}

In the period of therapy, we documented the formation of an abscess in one patient. One explanation is that it might have been coincidence. But former studies have shown a connection between atrophic nonunions and bone infection [30]. Therefor another possible interpretation might be that the biofilm of the implant has been mobilized by the ultrasound. This leads to the assumption that the use of LIPUS might be seen critically in patients after bone infection. A study in the US involving 55000 EXOGEN $^{\circledR}$ systems spanning 1 year of therapy showed that there was only skin irritation in three cases and chest pain in one patient, which may have been due to an interaction with a pacemaker [31]. Nevertheless, we believe that studies on LIPUS should not neglect possible complications due to the danger of the resurgence of a past infection.

\section{Comparison of groups}

Our study took the time to full weight bearing as well as the length of disability as functional outcome parameters. In unsuccessfully treated patients, full weight bearing took on average 3.7 months longer, the time to returning to work 6.8 months (Fig. 3).
The standardized subjective questionnaire showed that most patients were unsatisfied with the LIPUS therapy. More than half of patients $(70.5 \%)$ did not find LIPUS helpful in the standardized questionnaire (Table 6). Assumingly, this is due to the poor treatment result.

There was a significant difference in the age of the fracture in G1 and G2. Jingushi et al. found in their analysis of 72 patients treated with LIPUS that delayed fracture healing and nonunions should be treated within the first 6 months after the last operation [21]. Authors stated that $90 \%$ of fractures healed in patients in the first 6 months. If, however, LIPUS took place after the 6th month post-op, the success rate sank to $65 \%$. Nonunions heal in the first 6 months after surgical treatment anyway without further intervention in most cases, as shown in a study from 2009 with postoperative rates of healing between 80 and $100 \%$ [32]. For this reason, it does not seem meaningful to treat all patients with LIPUS.

We were able to show that plate osteosynthesis showed the best results, external fixation the worst (Fig. 4). This suggests that LIPUS is more appropriate for certain types of osteosynthesis. In this study we found that patients treated with plate osteosynthesis had a 6.0- (95\% CI 1.5-23.5) fold higher relative chance of success than patients treated with other surgeries. A Japanese research group found that patients treated with intramedullary nailing had a worse outcome with a relative risk of 4.5 (95\% CI 1.69-12.00) [14].

Watanabe et al. postulated that there are three key radiological factors that can influence the results of LIPUS: the gap size, the stability of the osteosynthesis, and the fracture classification [14]. In this prospective cohort study, 101 delayed fractures and 50 nonunions have been examined. The rate of consolidation was $68.0 \%$ (34/50) for patients with nonunion and $74.3 \%(75 / 101)$ for patients with delayed fractures healing.

Authors saw the gap size as a limiting factor for therapy. The results of our analysis are consistent with the literature, as we also found that the gap size influenced therapy results. A gap size of over $1 \mathrm{~cm}$ seems to be a contraindication for LIPUS [14, 15] (Table 5; Fig. 5a).

In our study, we found signs that previous infection influences LIPUS negatively (Table 4). Also the documented abscess may have been due to the influence of LIPUS. We found that patients with past osteitis had a 4.6(95\% CI 1.5-14.7) fold higher relative risk of treatment failure compared to patients without infection in prehistory. An association between LIPUS and previous infection of the bone has not yet been examined in previous studies. This aspect should be looked at in future studies. A summary of the discussed therapy related cofactors is listed in Table 7 . 
Table 7 Therapy related cofactors

\begin{tabular}{lll}
\hline Positive factors & Negative factors & $p$ value \\
\hline Plate osteosynthesis & External fixation & $0.012^{*}$ \\
Small defect & Large defect $(>1 \mathrm{~cm})$ & $0.034^{* *}$ \\
No infection in patients history & Osteitis in patients history & $0.012^{*}$ \\
Fracture age $<6$ months & Fracture age $>6$ months & $0.011^{* *}$ \\
Low NUSS Score & High NUSS Score & $0.034^{* *}$ \\
\hline
\end{tabular}

Listed cofactors show significant differences between the groups and should be considered in decisionmaking

* $\chi^{2}$ test

** Student's $t$ test

In the literature it is has been suggested that LIPUS has a biological effect $[16,17]$. It remains unclear whether this effect is clinically relevant or not [33]. However, it is uncertain if spontaneous healing is responsible for the documented success. A possible use of LIPUS is supportive treatment of nonunions in risk patients, but clinically and radiologically it is difficult to evaluate the use of LIPUS. An objective method for testing its effect could be the measurement and analysis of the serum cytokine profile that is involved in bone metabolism, e.g., TGFß-1, VEGF, PDGF, or bFGF [34], which can be evaluated objectively and have a small tendency towards bias [34].

\section{Conclusion}

In our patient collective, $32.8 \%$ of patients treated with LIPUS showed healing, despite strictly following indication criteria for EXOGEN ${ }^{\circledR}$. Following criteria should be considered prior to LIPUS therapy: mechanical stability, small gap sizes $(<1 \mathrm{~cm})$, short interval to treatment after injury, and the absence of acute or past infection. Such a collective actually has a high tendency towards spontaneous healing. In the remainder of patients, LIPUS lead to a significant extension of therapy and disability.

Our results show that LIPUS should not be seen as a generally accepted alternative therapy in the treatment of long bone nonunions. Furthermore its indications differ considerably from surgical ones. Therefore, LIPUS should be evaluated on a case-to-case basis.

Acknowledgments The presented results are part of doctoral thesis of Timur Mert Yildirim.

\section{Compliance with ethical standards}

Conflict of interest The authors have revealed all financial and personal relationships to other people or organizations that could influence this work. There are no conflicts of interest such as employment, stock ownership, honoraria, paid expert testimony, patents, grants, funding, or consultancies. Acknowledgment The presented results are part of doctoral thesis of Timur Mert Yildirim.
Open Access This article is distributed under the terms of the Creative Commons Attribution 4.0 International License (http://crea tivecommons.org/licenses/by/4.0/), which permits unrestricted use, distribution, and reproduction in any medium, provided you give appropriate credit to the original author(s) and the source, provide a link to the Creative Commons license, and indicate if changes were made.

\section{References}

1. Moghaddam A, Zimmermann G, Hammer K, Bruckner $T$, Grutzner PA, von Recum J (2011) Cigarette smoking influences the clinical and occupational outcome of patients with tibial shaft fractures. Injury 42(12):1435-1442. doi:10.1016/j.injury.2011.05. 011

2. Bishop JA, Palanca AA, Bellino MJ, Lowenberg DW (2012) Assessment of compromised fracture healing. J Am Acad Orthop Surg 20(5):273-282. doi:10.5435/jaaos-20-05-273

3. Kaminski A, Gstrein A, Muhr G, Muller EJ (2008) Transarticular C1-C2 screw fixation: results of unstable odontoid fractures and pseudarthrosis in the elderly. Unfallchirurg 111(3):167-172. doi:10.1007/s00113-007-1383-7

4. Rankin EA, Metz CW Jr (1970) Management of delayed union in early weight-bearing treatment of the fractured tibia. J Trauma 10(9):751-759

5. Goodship AE, Kenwright J (1985) The influence of induced micromovement upon the healing of experimental tibial fractures. J Bone Joint Surg Br 67(4):650-655

6. Gaston M, Simpson A (2007) Inhibition of fracture healing. J Bone Joint Surg Br 89(12):1553

7. Moghaddam-Alvandi A, Zimmermann G, Büchler A, Elleser C, Biglari B, Grützner PA, Wölfl CG (2012) Ergebnisse der Pseudarthrosenbehandlung mit "bone morphogenetic protein 7" (BMP-7). Unfallchirurg 115:518-526. doi:10.1007/s00113-0112100-0

8. Zimmermann G, Muller U, Loffler C, Wentzensen A, Moghaddam A (2007) Therapeutic outcome in tibial pseudarthrosis: bone morphogenetic protein 7 (BMP-7) versus autologous bone grafting for tibial fractures. Der Unfallchirurg 110(11):931-938. doi:10.1007/s00113-007-1347-y

9. Vogel J, Rompe JD, Hopf C, Heine J, Burger R (1997) Highenergy extracorporeal shock-wave therapy (ESWT) in the treatment of pseudarthrosis. Z Orthop Ihre Grenzgeb 135(2):145-149. doi:10.1055/s-2008-1039571

10. Rompe JD, Kullmer K, Vogel J, Eckardt A, Wahlmann U, Eysel P, Hopf C, Kirkpatrick CJ, Burger R, Nafe B (1997) Extracorporeal shock-wave therapy. Experimental basis, clinical application. Der Orthopade 26(3):215-228. doi:10.1007/p100003377 
11. Sharrard WJ (1990) A double-blind trial of pulsed electromagnetic fields for delayed union of tibial fractures. J Bone Joint Surg $\mathrm{Br} 72(3): 347-355$

12. Brighton CT, Black J, Friedenberg ZB, Esterhai JL, Day LJ, Connolly JF (1981) A multicenter study of the treatment of nonunion with constant direct current. J Bone Joint Surg Am 63(1):2-13

13. Duarte LR (1983) The stimulation of bone growth by ultrasound. Arch Orthop Trauma Surg Archiv fur orthopadische und UnfallChirurgie 101(3):153-159

14. Watanabe Y, Arai Y, Takenaka N, Kobayashi M, Matsushita T (2013) Three key factors affecting treatment results of low-intensity pulsed ultrasound for delayed unions and nonunions: instability, gap size, and atrophic nonunion. J Orthop Sci: Off J Jpn Orthop Assoc 18(5):803-810. doi:10.1007/s00776-013-0415-0

15. Roussignol X, Currey C, Duparc F, Dujardin F (2012) Indications and results for the Exogen ultrasound system in the management of non-union: a 59-case pilot study. Orthop Trauma Surg Res: OTSR 98(2):206-213. doi:10.1016/j.otsr.2011.10.011

16. Wei FY, Leung KS, Li G, Qin J, Chow SK, Huang S, Sun MH, Qin L, Cheung WH (2014) Low intensity pulsed ultrasound enhanced mesenchymal stem cell recruitment through stromal derived factor-1 signaling in fracture healing. PLoS One 9(9):e106722. doi:10.1371/journal.pone.0106722

17. Choi JW, Choi BH, Park SH, Pai KS, Li TZ, Min BH, Park SR (2013) Mechanical stimulation by ultrasound enhances chondrogenic differentiation of mesenchymal stem cells in a fibrinhyaluronic acid hydrogel. Artif Organs 37(7):648-655. doi:10. 1111/aor.12041

18. Alvarenga EC, Rodrigues R, Caricati-Neto A, Silva-Filho FC, Paredes-Gamero EJ, Ferreira AT (2010) Low-intensity pulsed ultrasound-dependent osteoblast proliferation occurs by via activation of the $\mathrm{P} 2 \mathrm{Y}$ receptor: role of the $\mathrm{P} 2 \mathrm{Y} 1$ receptor. Bone 46(2):355-362. doi:10.1016/j.bone.2009.09.017

19. Unsworth J, Kaneez S, Harris S, Ridgway J, Fenwick S, Chenery D, Harrison A (2007) Pulsed low intensity ultrasound enhances mineralisation in preosteoblast cells. Ultrasound Med Biol 33(9):1468-1474. doi:10.1016/j.ultrasmedbio.2006.12.003

20. Schofer MD, Block JE, Aigner J, Schmelz A (2010) Improved healing response in delayed unions of the tibia with low-intensity pulsed ultrasound: results of a randomized sham-controlled trial. BMC Musculoskel Disord 11:229. doi:10.1186/1471-2474-11229

21. Jingushi S, Mizuno K, Matsushita T, Itoman M (2007) Lowintensity pulsed ultrasound treatment for postoperative delayed union or nonunion of long bone fractures. J Orthop Sci: Off J Jpn Orthop Assoc 12(1):35-41. doi:10.1007/s00776-006-1080-3

22. Emami A, Petren-Mallmin M, Larsson S (1999) No effect of lowintensity ultrasound on healing time of intramedullary fixed tibial fractures. J Orthop Trauma 13(4):252-257
23. Lubbert PH, van der Rijt RH, Hoorntje LE, van der Werken C (2008) Low-intensity pulsed ultrasound (LIPUS) in fresh clavicle fractures: a multi-centre double blind randomised controlled trial. Injury 39(12):1444-1452. doi:10.1016/j.injury.2008.04.004

24. Handolin L, Kiljunen V, Arnala I, Kiuru MJ, Pajarinen J, Partio EK, Rokkanen P (2005) Effect of ultrasound therapy on bone healing of lateral malleolar fractures of the ankle joint fixed with bioabsorbable screws. J Orthop Sci: Off J Jpn Orthop Assoc 10(4):391-395. doi:10.1007/s00776-005-0901-0

25. Calori GM, Phillips M, Jeetle S, Tagliabue L, Giannoudis PV (2008) Classification of non-union: need for a new scoring system? Injury 39(Suppl 2):S59-S63. doi:10.1016/s00201383(08)70016-0

26. Paley D, Catagni MA, Argnani F, Villa A, Benedetti GB, Cattaneo R (1989) Ilizarov treatment of tibial nonunions with bone loss. Clin Orthop Relat Res 241:146-165

27. Zura R, Della Rocca GJ, Mehta S, Harrison A, Brodie C, Jones J, Steen RG (2015) Treatment of chronic ( $>1$ year) fracture nonunion: heal rate in a cohort of 767 patients treated with lowintensity pulsed ultrasound (LIPUS). Injury 46(10):2036-2041. doi:10.1016/j.injury.2015.05.042

28. Gebauer D, Mayr E, Orthner E, Ryaby JP (2005) Low-intensity pulsed ultrasound: effects on nonunions. Ultrasound Med Biol 31(10):1391-1402. doi:10.1016/j.ultrasmedbio.2005.06.002

29. Nolte PA, Avd Krans, Patka P, Janssen IMC, Ryaby JP, Albers GHR (2001) Low-intensity pulsed ultrasound in the treatment of nonunions. J Trauma 51(4):693-703

30. Dapunt U, Lehner B, Burckhardt I, Zimmermann S, Hansch GM, Ewerbeck V (2014) Evaluation of implant sonication as a diagnostic tool in implant-associated infections. J Appl Biomater Funct Mater 12(3):135-140. doi:10.5301/jabfm.5000205

31. Higgins A, Glover M, Yang Y, Bayliss S, Meads C, Lord J (2014) EXOGEN ultrasound bone healing system for long bone fractures with non-union or delayed healing: a NICE medical technology guidance. Appl Health Econ Health Policy 12(5):477-484. doi:10.1007/s40258-014-0117-6

32. Pieske O, Wittmann A, Zaspel J, Loffler T, Rubenbauer B, Trentzsch H, Piltz S (2009) Autologous bone graft versus demineralized bone matrix in internal fixation of ununited long bones. J Trauma Manag Outcomes 3:11. doi:10.1186/1752-2897-3-11

33. Bashardoust Tajali S, Houghton P, MacDermid JC, Grewal R (2012) Effects of low-intensity pulsed ultrasound therapy on fracture healing: a systematic review and meta-analysis. Am J Phys Med Rehabil/Assoc Acad Physiatr 91(4):349-367. doi:10. 1097/PHM.0b013e31822419ba

34. Zimmermann G, Henle P, Kusswetter M, Moghaddam A, Wentzensen A, Richter W, Weiss S (2005) TGF- $\beta 1$ as a marker of delayed fracture healing. Bone 36(5):779-785 